\title{
LEITURA NA PRISÃO FEMININA: da biblioteca ao questionamento dos gostos
}

\author{
Paula Sequeiros*
}

\begin{abstract}
Uma prisão feminina em Portugal foi caso de estudo sobre práticas de leitura nesse quotidiano. Consideram-se teorias sobre a prisão feminina (M.I. Cunha e C.R. Fonseca) e de uma perspetiva feminista e comparativa (M. Bosworth, B.H. Zaitzow \& J. Thomas). Para compreender o que, por que e com que significados as mulheres liam, cruzando dimensões sociais, desenhou-se uma abordagem qualitativa, metodologicamente diversificada (etnografia, entrevistas individuais e grupais com leitoras e com intermediadores), incluindo usos do espaço físico e social e do tempo, relações com familiares, com outras detidas e com pessoal prisional. Analisaram-se títulos favoritos (romances cor-de-rosa, literatura industrial, light ou kitsch), tendo-se em conta gêneros literários para públicos femininos e desconstruindo-se preconceitos de gênero e classe associados à sua crítica. A interpretação foi construída com um quadro teórico diverso (A. Amorós, M. Calinescu, R. Felski, J. Radway e M. Sweeney). A análise de práticas, concetualizações e representações desvelou traços interessantes e eventualmente inesperados sobre os modos de leitura.
\end{abstract}

Palavras-chave: Prisões femininas. Leitura. Literatura light. Literatura kitsch. Romances cor-de-rosa.

\section{INTRODUÇÃO}

A biblioteca do Estabelecimento Prisional Especial (EPE) de Santa Cruz do Bispo constitui uma localização social interessante para investigar leitura em bibliotecas, tendo em vista seu uso, em grande parte, por mulheres das classes populares, o que não é frequente em Portugal.

O objetivo central desta pesquisa foi o de compreender as práticas de leitura que se desenvolvem em tais condições, quais as preferências das detidas e as razões dessas preferências. Para além disso e nesse contexto, buscou-se identificar os significados que elas atribuem à leitura, como os constroem individual e socialmente, bem como o papel que atribuem agora à leitura na sua vida quotidiana. A análise levou em conta dimensões sociais, tais como classe, gênero, etnia, idade, ocupação e educação.

A média de idades das detidas tem aumentado nos últimos anos, o que vem reduzindo ainda mais o letramento (ou literacia, em Portugal) dessa população de baixa esco-

* Universidade de Coimbra - Colégio de S. Jerónimo. Largo D. Dinis, Ap ${ }^{\circ}$ 3087. Cep: 3000-995. Coimbra - Portugal.paulasequeiros@ces.uc.pt laridade. Tal realidade concreta foi confirmada, inicialmente, pelos dados recolhidos pela responsável do serviço educativo da prisão. Já os estudos que se referem ao baixo letramento (ou iliteracia em Portugal) frisam a forte relação entre baixo letramento e idade avançada. Entretanto, ao se cruzar essa variável com outras, como classe social baixa, gênero feminino (Ávila 2006; Lopes 2011), ou etnia cigana (Gomes 2003) sobrerrepresentada, como será visto adiante, a expectativa era de um nível de letramento bastante inferior ao da média da população portuguesa. Contudo, com uma disponibilidade de tempo certamente bem diferente da habitual fora da prisão, libertadas de tarefas domésticas e parentais, esperar-se-ia que a leitura ocupasse mais tempo das mulheres que detinham essa capacidade.

Tendo identificado que os itens mais requisitados eram romances da denominada literatura light, literatura de autoajuda e histórias trágicas de vida (misery lit) - designações amplamente usadas pela indústria livreira -, esta pesquisa deu um segundo passo, passando a focar-se também nos títulos e gêneros favoritos. Essa categorização é também questionada, dado 
que a literatura classificada frequentemente, e do ponto de vista do senso comum, como kitsch, ou cor-de-rosa, é rotulada, em alguns escritos acadêmicos, como light, industrial, ou de massas (Amorós, 1968; Cunha, 2004; d'Haen, Damrosch \& Kadir 2011). Tratou-se, então, de entender se existe alguma genealogia dessa literatura quanto a dispositivos estilísticos e narrativos e a conteúdos ideológicos, bem como se sua popularidade poderia ser explicada, ainda que parcialmente, pela utilização de dispositivos e conteúdos semelhantes. Para compreender o que atraía essas leitoras, realizou-se uma análise crítica de um título de cada gênero e foram comparadas as passagens favoritas selecionadas dentre vários títulos.

A biblioteca do EPE (feminino) de Santa Cruz do Bispo foi o terreno escolhido para um estudo qualitativo que visou a responder a essas questões e à sua evolução ao longo da pesquisa. A instituição, criada em 2004, é dirigida conjuntamente pelo Ministério da Justiça e pela Santa Casa de Misericórdia do Porto, instituição ligada à Igreja Católica. Um protocolo com o município da cidade de Matosinhos permite às mulheres sob regime aberto de detenção trabalharem em espaços públicos, executando tarefas como jardinagem e limpeza. Nesse âmbito ainda, as detidas fruem do serviço móvel da biblioteca municipal.

ثิ A biblioteca, contígua às salas de aula, é é gerida pela técnica responsável pelo serviสิ่ ço educativo. Uma detida é responsável pela si manutenção e pelo atendimento às usuárias. Contém cerca de 8000 livros, em grande parte oferta da Fundação Calouste Gulbenkian, algu¿ mas revistas e um jornal diário, dois computa\& dores sem acesso à Internet - possível só em 今ิ aula, com orientação da professora - e algumas

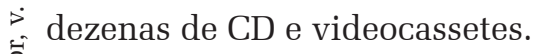

\section{SISTEMA PRISIONAL E LEITURA}

A história da prisão moderna é genderizada desde o seu início, nos finais do sécu- lo XVII, tendo sido moldada por normas patriarcais quanto à sexualidade feminina. Nos hospícios, eram detidas não só as mulheres moralmente perigosas, prostitutas na sua maioria, mas também as que desafiavam a moral dominante, que podiam ser entregues por pais e pares masculinos, se entendessem que a reputação familiar estava em jogo. A correção era imposta através de trabalhos femininos e da prédica religiosa (Bosworth, 2000). Recentemente a população feminina encarcerada cresceu fortemente em diversos países, refletindo-se a moral de género no tratamento discriminante que lhe é conferido pelos sistemas penal e prisional (Fonseca, 2010; Myers, 1996).

Perante a destruição progressiva do Estado social, as camadas mais despossuídas e marginalizadas das classes trabalhadoras, nas sociedades pós-industriais, passam a ser sujeitas à ação punitiva do Estado neoliberal, que assume agora uma "regulação punitiva da pobreza”, a que se adicionam a segregação racial e a marginalização espacial nos bairros pobres (Wacquant, 2012).

O discurso dos sistemas penais foi já centralmente construído em torno da reabilitação, sendo a leitura usada frequentemente como instrumento de controle pelas autoridades prisionais. Nesse sentido, as bibliotecas foram instrumentalmente pensadas e orientadas para a biblioterapia (Sweeney, 2008). Posteriormente, com os resultados de tais programas fortemente questionados, o direito a ler, por si só, pôde ser invocado como justificação central para a existência de tais bibliotecas (Barone, 1977), contrariando as práticas usuais que instrumentalmente associam leitura ao ensino ou ao melhoramento pessoal.

Se esses posicionamentos são conhecidos no que diz respeito ao papel da leitura concebido pelos poderes institucionais, as detidas podem, por seu lado, investir na leitura com diferentes finalidades: recuperar a humanidade de que o aprisionamento as privou; reavaliar histórias e percursos pessoais; aprofundar o autoconhecimento; atribuir novos significados 
à sua vida através de experiências vicariais; experimentar novas posições, como sujeitos, em processos identitários (Mendes, 2001), de tipo projetivo (Sweeney, 2004); e ainda melhorar a autoestima e o letramento (Perez Pulido, 2010).

A seguir, para o enquadramento da leitura no Estabelecimento de Santa Cruz, evocarei estudos de diversos casos. Amplamente utilizados foram os de Manuela Ivone Cunha (2002) e de Cristina Reis Fonseca (2010).

Para análise dos textos favoritos selecionados neste caso, comparei gêneros, recorrendo ao conceito de "novela rosa" de Amorós (1968) e ao de kitsch segundo Calinescu (1987). Os conceitos de light e kitsch são discutidos de acordo com teorias sobre o gosto, tendo em conta perspectivas de classe social, de gênero e algumas análises de contexto histórico. As abordagens feministas do kitsch e da literatura light foram especialmente consideradas.

O trabalho de identificação e questionamento de conceitos e teorias que apresentarei - que se foram ampliando e associando por exigência interpretativa - e a reflexão própria sobre eles serão apresentados paralelamente à apresentação dos dados empíricos recolhidos, sem um quadro teórico fixo posto de antemão. Dessa forma, pretendo não só retratar o ritmo de vaivém da teoria à empiria como proporcionar uma leitura de resultados e conclusões que possa envolver quem lê de forma análoga à que eu própria experimentei. Esse processo foi-se enriquecendo à medida que a interpretação de resultados o requeria, ou até mesmo pelo encontro (quase) ocasional de mais produção teórica que fui incorporando nas várias fases da pesquisa.

\section{As reclusas}

Alguns dados sociodemográficos atualizados foram coligidos a partir de estatísticas do EPE. Do trabalho sobre ele de Fonseca (2010) foram usados os dados estatísticos restantes, chamando à comparação os resultados da década anterior para a prisão feminina de Tires, concelho de Lisboa, reportados por Cunha (2002).

A população detida tem crescido nas últimas décadas sem aparente conexão com a evolução dos níveis de criminalidade (Wacquant, 2010). Portugal tem um dos números mais elevados de condenadas na UE, com características demográficas particulares: várias mulheres são condenadas simultaneamente com parentes e vizinhos do bairro social, na sequência da repressão ao tráfico de drogas ilícitas que passou a estar policialmente centrada nesses bairros (Cunha, 2002). Então, cerca de $9 \%$ dos detidos em Portugal são mulheres, as quais parecem ser objeto de uma aplicação da lei penal assente em pressupostos patriarcais, uma vez que os papéis de gênero, mais do que a lei, têm evidenciado uma saliente função discriminatória nessas condenações (Matos \& Machado, 2007).

$\mathrm{Na}$ verdade, o estatuto duplamente desviante usado no discurso jurídico - que classifica essas mulheres como criminosas e, simultaneamente, transgressoras das expectativas dominantes de gênero - pode se refletir em sentenças mais pesadas no caso de crimes com violência, supostamente contrária à sua condição feminina "natural" (Fonseca, 2010). De acordo com esse duplo estatuto, também a reabilitação moral das mulheres é promovida pela formação em cuidados domésticos, com crianças e com a família (Cunha, 2002).

Prisão e pobreza estão intimamente ligadas na vida das reclusas. Muitas das que trabalhavam fora de casa faziam-no em atividades de economia formal ou informal, sem proteção social. Entre o bairro e a prisão (Cunha, 2002), a maioria dessas mulheres é apanhada num círculo de pauperização de que o tráfico é simultaneamente produto e produtor. Frequentemente, mulheres estrangeiras são também condenadas como correios de droga (Fonseca, 2010).

Importa mencionar ainda que o controle de comportamentos pode ser alcançado com uma multiplicidade de recursos, desde a aplicação de regras e horários uniformes até atitudes paternalistas de gestores e de pesso- 
al, levando a população detida a um estado de "incapacidade aprendida" (Zaitzow \& Thomas, 2003).

\section{A CONSTRUÇÃO DO CASO}

Desenhou-se uma abordagem qualitativa, teoricamente suportada, apoiada numa concepção metodológica integrada e diversificada. O trabalho empírico decorreu de fevereiro a outubro de 2012. As práticas de leitura foram pesquisadas no seu contexto através de um conjunto de ferramentas progressivamente adaptadas às dificuldades inerentes às condições do terreno e às sugestões das próprias: observação etnográfica; entrevistas semiestruturadas, em profundidade, com oito mulheres; conversas informais com presas, guardas prisionais, profissionais do serviço social e responsáveis pela gestão; uma sessão de grupo focal com seis leitoras; relatos de vida escritos por detidas. Uma amostra das detidas foi construída de forma a refletir a diversidade revelada pela caraterização estatística quanto à classe social, idade, educação, etnia, ocupação e frequência de visitas à biblioteca prisional. Usaram-se nomes fictícios para designá-las. Note-se que, apesar da vontade expressa generalizada de colao borar na pesquisa, o próprio ciclo de vida da S prisão nem sempre permitiu um acompanhamento sistematizado das informantes.

En Enfocaram-se, em especial, os títulos $\rightarrow$ preferidos de um tipo específico, a literatura light, dado esse ser um tema ainda pouco investigado, sobretudo do ponto de vista da ¿ recepção das próprias leitoras. Esses títulos $\dot{a}$ foram analisados tendo em conta a estrutura of narrativa e as personagens, o estilo e ainda os ti temas e posicionamentos ideológicos.

\section{O Estabelecimento de Santa Cruz do Bispo}

O edifício prisional apresenta um desenho funcional, integrando materiais de boa qualidade. As detidas estão distribuídas por quatro alas, uma delas com celas para mães e crianças e creche. As celas estão frequentemente personalizadas com aparelhos de televisão e de rádio, além de cortinas de cores vivas. As presas podem trabalhar algumas horas por dia, geralmente em tarefas subqualificadas. Além da escola e das oficinas, frequentam atividades organizadas, tais como a catequese.

Alguns dados estatísticos apoiam esse retrato: dados nacionais para 2011 (indicados entre colchetes), e dados do Estabelecimento. No final de 2011 havia 281 presas, e um terço estava em regime preventivo. Quase dois terços tinham entre 30 e 49 anos. Cerca de $15 \%$ eram estrangeiras [3.9\%, estrangeiros residentes]. Passaram pelo ensino básico (4 a 6 anos) 60\% [35,4\%]; cerca de 14\% eram iletradas [6,8\%]; menos de $4 \%$ eram licenciadas [13.6\% em 2010]. A maior parte trabalhava fora de casa, algumas eram donas de casa ou desempregadas e uma pequena parte era aposentada. A atividade econômica mais comum fora de casa era a de vendedora ambulante ou em feiras. Em 2010, segundo Fonseca (2010), a maioria era de etnia branca, e a etnia cigana ${ }^{1}$ atingia $17 \%$ (para $0,06 \%$, estimados no país em geral) e a negra 1,6\%. A grande maioria residia no Norte. Drogas e crimes relacionados com entorpecentes representavam 58,5\% das condenações, enquanto $35,9 \%$ das detidas reincidiam pela segunda vez, pelo menos. A grande maioria era constituída de mães (Fonseca, 2010). Podiam ter "visitas íntimas" (Nogueira, 2012) uma vez por mês, casadas ou não, mas apenas uma percentagem muito baixa realmente as recebia - 9,6\% em 2010. As visitas de familiares eram realizadas aos domingos.

Note-se que esse Estabelecimento Penal tem estatuto "Especial" e caraterísticas que o tornam singular no panorama prisional português.

${ }^{1}$ Uso o termo cigana dado ser o adotado pela própria comunidade rom em Portugal. 


\section{A atmosfera na prisão}

A prisão assemelha-se a um hospital, com os seus longos corredores e instalações muito limpas. Guardas femininas vigiam as alas das celas, e guardas masculinos asseguram a segurança geral. O ambiente é estranhamente calmo, nenhuma tensão aflora claramente, especialmente fora dessas alas. A contenção emocional e a aparente depressão assomam em muitos rostos, ocasionalmente marcados pelo choro. Medicação e terapia ocupacional são comumente usadas para modular comportamentos.

A revolta e o ressentimento por tratamento injusto parecem ser mais comuns após os primeiros meses de encarceramento, especialmente para quem afirma ter sido injustamente condenada. É provável que parte dessas mulheres tenha sofrido abusos de familiares masculinos - pelo menos metade, segundo estudos dos EUA (Ferraro \& Moe, 2003; Sweeney, 2004). Uma das técnicas afirmou que, pelo seu conhecimento empírico, esse mesmo dado se aplica nessa prisão, embora as próprias detidas possam não conceber essas situações como abusivas. Muitas sofrem de toxicodependência. A detenção pode, assim, ser sentida, paradoxalmente, como alívio, pelo menos parcial (Matos \& Machado, 2007; Zaitzow \& Thomas, 2003), como algumas mulheres me confidenciaram: a prisão tinha-lhes proporcionado as condições de tratamento às quais não tinham conseguido acesso antes. Devo, aliás, acrescentar que guardo a impressão de ser a inculcação dessa melhoria comparativa usada como um meio adicional de submissão.

Áreas comuns - como escola, oficinas, biblioteca ou até a capela, ocasionalmente adaptada para ginásio - são lugares de convívio discreto, pois conversas privadas não são permitidas.

Guardas femininas mostram, por vezes, uma condescendência maternal:

Vá lá, limpe essas lágrimas, arranje-me essa cara, e não a quero ver assim outra vez.

Lembre-se disto, não se envolva com o tipo errado de pessoas, aqui!
Pegue neste livro, leia, vá ao ginásio, ${ }^{2}$ vai sentir-se melhor.

A avaliação de atos passados conducentes à prisão e as ideias sobre um futuro lá fora são expressas em discursos frequentemente matizados por um tom (religioso?) de melhoramento pessoal, sendo a condição atual referida, paradoxalmente, como "oportunidade" para aperfeiçoamento. Assumindo a conformidade e a submissão ao sistema como facetas do sistema prisional, podem as detidas ter internalizado o seu discurso institucional (Goffman, 1961). Além do mais, pareceu-me que recorrer a esse discurso legitimado seria estratégia de defesa muito provável em ambiente de permanente vigilância e onde a minha presença se pôde tornar alvo de desconfiança, o que episodicamente registei. Manuela, ${ }^{3}$ por exemplo, explica que provavelmente teria morrido se a sua toxicodependência não tivesse sido ali tratada - tal como a dentição o fora -, o que não conseguira lograr no exterior. Sente que recuperou o controle sobre sua vida e sente-o como realização pessoal e exemplo para os filhos. Com aulas de artes e ofícios, e com atuação teatral, as mulheres descobrem, como mencionaram, muitas vezes, Celeste ${ }^{4}$ e Margarida, ${ }^{5}$ formas de expressão e criatividade que "não sabíamos que tínhamos dentro de nós". Frequentando a escola, lendo autores até aí desconhecidos, elas vislumbram realidades e experimentam emoções que lhes ampliam horizontes. Essas atividades podem reinvesti-las com traços de sensibilidade que a condição de presas lhes roubara e dar lugar à valorização e ao reconhecimento por terceiros, dentro e fora da prisão, como foi o caso de uma performance teatral que teve cobertura dos meios de comunicação.

Contudo, isso não significa uma assunção de justiça. Não significa tampouco que,

${ }^{2}$ Em Portugal, um espaço desportivo.

${ }^{3}$ Manuela: 50 anos, classe baixa, a completar o $9^{\circ}$ ano.

${ }^{4}$ Celeste: 43 anos, técnica do terciário, classe média baixa $12^{\circ}$ ano, estudou no estrangeiro.

${ }^{5}$ Margarida: 41anos, técnica da indústria, classe média baixa, $12^{\circ}$ ano. 
pelo seu olhar ou pelo de terceiros, elas não representem a prisão como uma "escola de crime", sítio onde se aprende a "refundir" droga e onde se pode ser atraída para o tráfico. Um dos traços mais perturbantes para o seu quotidiano, e que infundia um sentimento de injustiça, era um uso excessivo de regras, frequentemente tácitas, que constantemente mudavam, mas cuja violação seria razão para castigo. Já uma importante aprendizagem feita dentro do sistema é a do aproveitamento de cada oportunidade para combater a solidão e para obter capacidades e recursos cognitivos ou emocionais, aprendizagem constituída como uma forma de resistir à despersonalização e de alimentar esperança numa vida melhor. Maria João ${ }^{6}$ estabelece uma curiosa associação entre esse ambiente e o do "colégio interno católico" que frequentou, contra sua vontade, quando adolescente: "[...] só que este é mais brando". Kadija ${ }^{7}$ explica como chegou àquela situação: "Sempre trabalhei, como meu marido. Trabalhei com limpezas, às vezes no $\mathrm{X}$ [nomeia cadeia de supermercados]. Depois, compramos essas coisas e ele queria voltar lá (na Guiné-Bissau) para trabalhar e eu não queria, não queria deixar os meus (quatro) filhos cá. Depois, em 2009, começa não haver trabalho, eu tinha carro, filhos, coisas para pagar, é @ quando é essa desgraça, eu fui buscar droga”.

A evocação dos laços familiares, com os filhos em especial, foi sempre central nas suas narrativas, sabendo-se que, mesmo na prisão, as mulheres mantêm um significativo papel de cuidadoras, como traço caraterístico de gênero (Cunha, 2002). $\dot{9}$

\section{Leitura e biblioteca, antes e durante}

Sem catálogos, os livros são arrumados por temas. Em geral, as leitoras não percorrem

${ }^{6}$ Maria João: 54 anos, profissional das artes, curso superior, oscilação frequente entre classe média e baixa, estudou no estrangeiro.

${ }^{7}$ Kadija: 51 anos, classe baixa, $6^{\circ}$ ano de escolaridade. prateleiras, pois consultam a "colega" que trabalha na biblioteca. "Lê isto, vai te fazer bem!", aconselha ela. Esse aconselhamento, seguido pelo das professoras, revelou-se, aliás, o mais apreciado e disponível "sistema de referência” bibliotecário. Os pedidos por lazer ou por estudo recaem sobre diminuta parte da coleção, pois os livros oferecidos raramente lhes respondem, numa falta de adequação já mencionada por Eiras (2007), que alude às preferências do leitor recluso (masculino): poesia, romance e, depois, histórias em quadrinhos ${ }^{8} \mathrm{e}$ policiais, por ordem decrescente.

Contrariamente às alas, a biblioteca é sentida como um lugar calmo. A conversa, não autorizada, faz-se aí com recato. A leitura fazse depois, em geral nas celas, à noite, quando o tempo "custa tanto a passar".

Embora ler possa não ter sido sequer uma possibilidade para algumas delas, "há ciganas que sabem ler!”, exclama Maria, ${ }^{9}$ com sorriso confiante, orgulhoso. Impedidas pelos pais - no caso de Maria - ou pelos maridos - no caso de Dayara ${ }^{10}-$, de ir à escola, ao contrário dos rapazes, podem obter agora um certificado de ensino secundário na prisão.

Em geral, os livros não tinham sido nem seus conhecidos nem próximos, pois a compra era inacessível às de famílias de menores rendimentos. Duas mulheres recordaram que a feira do livro era, na sua infância, oportunidade única no ano para que lhes comprassem um.

A leitura de jornais foi e ainda é um hábito para apenas umas quantas, já que a maioria prefere assistir aos noticiários nas celas. As revistas disponíveis não são muito apreciadas, exceto as de trabalhos manuais. Curiosamente, as revistas "femininas" centradas na vida de socialites foram objeto de escárnio por duas das mais jovens entrevistadas. Diz Helena: ${ }^{11}$

\footnotetext{
${ }^{8}$ Gibis, na designação corrente no Brasil.

${ }^{9}$ Maria: 55 anos, a completar o $9^{\circ}$ ano.

${ }^{10}$ Dayara: 30 anos, vendedora ambulante, a completar o $9^{\circ}$ ano.

${ }^{11}$ Helena: 18 anos, família proprietária de lojas, a completar o $9^{\circ}$ ano.
} 
"São coisas que não me dizem nada", os comentários sobre vidas alheias "nas revistas, na televisão, no dia a dia”. São, em geral, folheadas descuidadamente, para passar o tempo.

Visitar a biblioteca era um hábito novo: encontrei raras frequentadoras prévias e, entre elas, uma só fora visitante frequente antes da prisão. Quase todas as inquiridas argumentaram que, com as ocupações familiares, não tinham o tempo desejado para ler. A leitura tornara-se mais frequente para quem entrara já como leitora intensiva. Algumas declararam ainda que essa biblioteca lhes apresentara autores e títulos que, provavelmente, não teriam conhecido no seu curso normal da vida.

Após a prisão, algumas mulheres recuperaram ou reforçaram uma prática de intimidade:

Aqui, encontrei-me de novo na literatura (Manuela). Sabe quem é o meu melhor amante, todas as noites? É um livro, porque eu durmo com esse livro e tenho muitas emoções! (Margarida).

Apesar da relativa homogeneidade social dessa população prisional, as opções de leitura variam interindividualmente em gêneros e tipos de textos - poesia, romance, romances históricos ou policiais, livros de autoajuda, biografias trágicas, culinária, jornais, revistas -, havendo lugar para variações intraindividuais também, ao longo do período de aprisionamento (Horta \& Marques, 2008). Alguns autores aclamados, referidos na imprensa, incluindo escritores "sérios", são ocasionalmente objeto de pedidos locais - José Luís Peixoto, Mia Couto, Mario Benedetti - ou, excepcionalmente, re-endereçados para o serviço móvel municipal. Os gêneros mais solicitados são o romance cor-de-rosa, as histórias trágicas de vida - incluindo as que tomam a prisão ou as drogas como tema central -, o romance de autoajuda e a poesia erótica. Atente-se que as escolhas são condicionadas pela disponibilidade no local e que a biblioteca municipal, com limitações de pessoal, não reunia, naquele momento, condições para proporcionar atendimento cuidadoso nem resposta adequada aos interesses expressos. Kadija, por exemplo, manifesta o seu desapontamento por não haver, na prisão, "mais livros de autores africanos", pois diz apreciar livros que tenham a ver com a África, onde nascera.

Mulheres mais jovens, ocasionalmente, jogam no computador. Assistir a vídeos é uma atividade apreciada, e há visitantes regulares da biblioteca com esse fim.

Romances cor-de-rosa, ainda que lidos avidamente, "não precisam ser verdade" afirmam, fazendo questão de demonstrar a consciência de sua ficcionalidade. Alguns títulos favoritos estão constantemente emprestados. Projetar-se em personagens, viver vicariamente suas experiências, aferir atos próprios com os dessas personagens e imaginar vidas alternativas foram frequentemente mencionados como atitudes fundamentais num trabalho introspetivo intenso realizado por mulheres em processos de acerto de contas com o passado e que estão planejando um futuro pós-saída (Sweeney, 2008; 2010). "Vou ver se sou uma boa mãe", disse Maria João, lendo um livro recomendado na TV. "Já estou nos 50, [mas] se eu tivesse projetado aquela alternativa que encontrei no livro, talvez a solução [do problema que a levou à condenação] tivesse sido diferente", declarou Margarida. "Estamos sempre à espera de que haja passagens, frases, que se identifiquem com as nossas vidas”, explica Maria João.

Tentei perceber se os hábitos de leitura haviam mudado após a detenção. Com respostas negativas, entendi, contudo, que as mulheres pretendiam assim reforçar autorrepresentações identitárias, como se tivessem permanecido intocadas por um ambiente construído como moralmente negativo. A questão aclarou-se depois: se não mudaram as práticas, mudaram os seus significados. Privadas de liberdade, lidando com culpa, arrependimento, solidão, raiva, saudade, resistindo a processos de homogeneização na prisão, investindo em práticas identitárias individualizantes de cuidados pessoais, de decoração das celas, a vida afetiva tornara-se diferente: "Aqui dentro, sob 
detenção, sentimos tudo de uma maneira mais forte”, explica Margarida. "A dobrar...", atalhou Celeste. "Vivemos tudo mais intensamente!", concordou Maria João. Novos significados são construídos, incluindo para o que se relê.

Emocionalmente, um papel importante

é atribuído à leitura, frequentemente descrita como um "remédio sagrado" para chamar o sono, "terapia”, “consolação”, "escape”, mas também "adrenalina”, promovendo a "excitação", ausente numa vida espartilhada pelas rotinas.

Daqui a única coisa boa que levo é a escola, porque,
de resto, é dia após dia, dia após dia... O cérebro
cada vez fica mais lento, cada vez me sinto mais
distanciada da sociedade, com mais medo do que
vou encontrar. Porque é muito tempo isolada! Mas
eu não sou ninguém para ir contra o sistema. Por
isso, tenho que aguentar (Helena).

As histórias trágicas de vida são, por isso, apreciadas. Ler Christiane $F .^{12}$ fez Helena sentir-se "bem", pois ela também tinha "conseguido sair da droga”. Poemas eróticos, do livro Con-sensual-idade de Teresa Machado, um dos mais pedidos, são usados para escrever cartas de amor, em analogia, aliás, com outras prisões (Álvarez \& Álvarez, 2011; Sweeney, 2010). "Fazer as nossas coisas" - trabalhos manuais, escrita e artes - pode, aqui, "tornar-se quase um vício”, declarou Margarida.

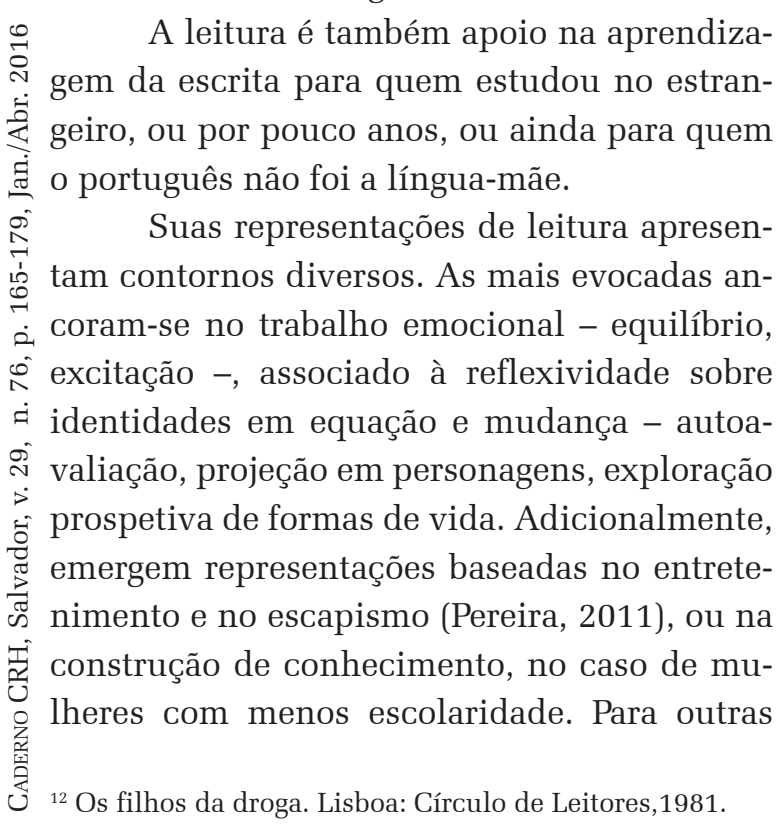

leitoras, mais intensivas e experientes, com modos de leitura cumulativos, as representações são complexas, combinando várias imagens representacionais.

\section{Os títulos favoritos}

Conhecidos os títulos mais requisitados e os sinalizados nas entrevistas como favoritos, decidi focar a minha análise no gênero de longe mais popular: o romance cor-de-rosa da literatura light ou industrial. Livros de autoajuda seguem-se na ordem de referências, juntamente com as histórias de vida dramáticas. Alguns dos títulos cor-de-rosa mais lidos apresentavam também uma faceta de autoajuda, o que as leitoras haviam já sinalizado. Acontece, contudo, que autoras e autores podem classificar a si próprios diferentemente: Modignani fala de "romance cor-de-rosa", Paulo Coelho de "esotérico" ou "autoajuda" e Margarida Rebelo Pinto insiste em "pop", vincando, assim, a intenção de se opor a uma postura intelectual alegadamente adotada nas obras dos seus críticos. Comumente, essa literatura é referida também como kitsch.

Para as leitoras do grupo focal há, no entanto, uma única categoria de romance, que subentendem ser "romântico". Um bom romance, consideram, deve simultaneamente conter personagens com quem sintam empatia e uma escrita adequada às suas capacidades de leitura. Deve, ainda, proporcionar prazer, ou, pelo menos, um final feliz ou reparador.

Surgiram, então, novas questões. Como e porque valorizam esses títulos e que traços as atraem mais? Alguma genealogia literária pode explicar, mesmo que parcialmente, o seu sucesso?

Uma análise comparativa das características principais das três obras focou-se nos dispositivos narrativos e estilísticos e nos conteúdos temáticos e (ou) ideológicos. Do elenco total de títulos preferidos, escolhi três dos mais populares: Um sonho de vida de Nora Roberts (2005), Onze minutos de Paulo Coelho (2007) e 
Uma chuva de diamantes de Sveva Casati Modignani (2006).

Às leitoras pedi que, de cada obra, selecionassem as duas ou três passagens favoritas. Sem surpresa, as três que revelaram menos dificuldade nessa tarefa eram as leitoras mais ávidas, antes e durante o tempo de prisão. As seleções evidenciam a evocação de situações semelhantes às vividas pelas próprias leitoras, enredos e personagens que lhes servem de referência e ponto de aferição. Apenas um comentário a Uma chuva de diamantes referia-se a opções estilísticas - "um jorro quente de lágrimas", tão mais bonito do que simplesmente "chorar", explicou Celeste.

Como nota final, destaco a importância da leitura nas sociabilidades das reclusas, incluindo nos processos informais e grupais de formação de opinião sobre o que leem.

\section{Comparação entre títulos e linhagem literária}

A seguir, comparo sumariamente enredos e personagens dos três romances. Depois, abordo os conceitos de literatura cor-de-rosa e kitsch e sua aplicabilidade aqui. Por fim, confronto os resultados dessa análise comparativa com as razões de preferência declaradas.

Os três romances evidenciam o uso de fórmulas literárias que não são novas. A narrativa centra-se numa mulher de classe baixa, em ascensão social por ligação a um homem rico e mais velho. $\mathrm{O}$ amor - aqui sinédoque para o amor heterossexual - acontece, "naturalmente", à primeira vista, e pode ser ameaçado por problemas sexuais que só um verdadeiro amor supera. As heroínas, ainda que personagens autônomas, com ideias próprias, inicialmente avessas ao ato de se apaixonar, acabam por ceder, cumprindo, assim, o papel do ser imperfeito, que se completa no casamento e, talvez, na maternidade, na linha do ideal platônico do encontro entre "almas gêmeas". Os protagonistas masculinos, maduros em idade e mentalidade, calmos e fortes, são ricos, pro- porcionando um perfeito apoio financeiro e emocional à parceira. Os seus nomes podem ter um toque aristocrático (Byron de Wit, em Um sonho de vida). De contornos pouco claros, os retratos físicos e psicológicos facilitam a projeção emocional. Trabalho ou dinheiro são questões rodeadas de omissões, pois as fortunas simplesmente acumulam-se, mesmo em circunstâncias adversas. Os problemas sociais ora estão ausentes, ora, se nomeados, são logo descartados (a guerra, em Modignani) ou ridicularizados (manifestações de curdos, em Coelho). As estruturas narrativas estão permeadas por inconsistências - aliás, facilmente identificadas por fãs, segundo posts em sites como Goodreads, blogs pessoais ou livrarias on-line. O mesmo se aplica à repetição de enredos e situações. Não apenas esse último traço, como o anterior, são muito provavelmente o resultado previsível de uma escrita em massa, podendo seus autores chegar a lançar vários títulos por ano. As personagens podem aparecer em mais de um livro, em similaridade com as novelas e séries de TV, como é o caso da série Sonho de Modignani. Alguns ambientes de interiores domésticos, aliás, fizeram-me amiudadamente recordar imagens de propaganda comercial, já com várias décadas.

\section{A “novela rosa”, segundo Amorós}

Todos esses traços são coincidentes com os que Amorós usa para caracterizar a denominada "novela rosa", de 1946 até o presente, e em que sobressaiu a autora Corín Tellado. A diferença mais evidente reside no fato de que as protagonistas contemporâneas são investidas de caráter mais forte. Os homens não são necessariamente o lado do par que resiste a casar; pelo contrário, as mulheres estão agora dotadas de alguns desses traços de estereótipos masculinos. Cinquenta anos depois, essas mulheres são ainda retratadas como sujeitos secundarizados: se "emancipadas”, é o estereótipo patriarcal que as apresenta como masculi- 
nas, sem emoções, atributo de que se libertam, por fim, por intervenção do herói com quem contracenam.

O uso de dispositivos estilísticos anteriormente abundantes - tais como a adjetivação afetada - não ocorre frequentemente nos três casos. O melodramatismo extremo já não é ingrediente básico. Os dispositivos literários parecem, aliás, restritos a um mínimo.

Ao contrário de Amorós, não presumo que o uso de linguagem coloquial, encontrada igualmente nessas obras, deva ser considerado marcador distintivo da literatura rosa ou industrial, pois autores contemporâneos também fazem esse uso na literatura enquadrada pelo cânon acadêmico.

\section{Literatura industrial e kitsch}

Grupos da classe média do século XIX alimentaram, ideologicamente, os fundamentos estéticos do kitsch, segundo Calinescu (1987), ao pretenderem imitar o gosto da aristocracia deposta. Atualmente, uma referencia de classe à aristocracia será inadequada, embora alguns traços do kitsch persistam na literatura industrial. A burguesia alta parece ter tomado o lugar dos aristocratas, pois as aspirações oriundas do - meio da escala social refletem agora traços do ๙ seu (suposto) modo de vida. \& camadas inferiores da classe média podem ser iิ "a classe social com a mais baixa reputação em

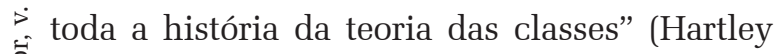
apud Felski, 2000, p. 46), com uma "identidade negativa”, não tendo "nada a declarar" quanto à mudança social, frisa Felski (2000).

Essa classe média mais baixa está hoje fortemente feminizada, com as mulheres constituindo uma grande parte do trabalho no setor terciário. Alguns valores tradicionalistas estão também associados às mulheres: "domesticidade, puritanismo, aspirações dirigidas ao refinamento" (Felski, 2000, p. 48). Assim, a literatura industrial aparenta uma aproximação da classe média baixa, à medida que ela se torna mais letrada. Efetivamente, kitsch e light-lit (chick lit, como por vezes é designada também) partilham esse rótulo de feminilidade. É um exercício interessante, contudo, comparar a rotulagem de romances industriais rosa ou de revistas femininas e outras formas de escrita consideradas "inferiores", segundo o cânon. Se comparados com os jornais desportivos, com um análogo papel de gênero de lazer, os preconceitos afloram, já que esses últimos não são objeto de análoga depreciação.

\section{Uma receita de sucesso comercial}

Comparo, em seguida, as principais características desses romances industriais com as do kitsch, usando a perspectiva de Calinescu (1987).

Consideremos, primeiro, a evitação do risco, caraterística fundamental, consubstanciada em "repetição, banalidade, trivialidade" (Calinescu, 1987, p. 226). Tanto o kitsch como o light são produtos culturais do industrialismo e, talvez até mais claramente, para Calinescu, produtos do espírito de decadência gerado pelo sistema capitalista industrial. Presentemente, os romances são escritos de acordo com uma fórmula de produção em massa, automatizada, traduzidos para uma grande variedade de línguas: a tecnologia facilita a produção e difusão, e a comercialização é planejada em escala global. As vendas já não são medidas em milhares, mas em milhões de exemplares. Expostas em toda a parte, desde supermercados e postos de correios até tabacarias, essas novelas são promovidas por grandes livrarias e cadeias, em lançamentos espetacularizados, a preços baixos, com capas e títulos cativantes. Os autores light, frequentemente inseridos no 
sistema de estrelato televisivo e publicitário, chegam a ser recrutados pelos editores entre apresentadores de notícias e copywriters (Pinho, Teixeira e Ferreira, 2009).

Em seguida, consideremos o kitsch como literatura baseada em "sensações falsas", "experiência vicarial" e "uma estética de decepção e autodecepção" na ótica de Calinescu (1987, p. 229). Um sentimentalismo feito de lembranças de um passado idílico, de "[...] fantasias que servem de pontos cálidos nas nossas vidas frias [...] lembrando-nos que as coisas foram boas outrora e que as coisas podem ficar boas de novo", é talvez o seu elemento mais marcante, comenta Felski (1990, p. 10-11). Nos romances rosa atuais, a nostalgia não está necessariamente vinculada a fatos das vidas das heroínas; está, sim, claramente associada a modelos regressivos de papéis de gênero, caso da persistência do estatuto de mãe e mulher casada como condição para uma vida perfeita.

Se considerarmos o efeito de relaxamento hedonista, tanto um como outro estilo propiciam resultados semelhantes. O hedonismo, em Calinescu, aparece intimamente ligado a um centramento num eu dessocializado, talvez ligado a um autoaperfeiçoamento dirigido à supremacia individual, como resposta aos problemas da vida quotidiana. O excesso, no âmbito das relações amorosas, antídoto e salvação para um quotidiano entediante, é não só permitido como, aparentemente, esperado. No final feliz reside a "promessa de uma catarse fácil” (Calinescu, p. 228).

Por fim, o kitsch é concebido como inadequação estética por mobilizar temas e apropriar-se, de forma estranha, fora de contexto, de partes de obras com anterior alto estatuto. A literatura light pode, ainda e ocasionalmente, ir buscar referências aristocráticas, embora pareça assente em ambientes descaracterizados, ou do tipo manta de retalhos eclética, facilitando o marketing para um público vasto. O estilo tende a ser lhano, e o nível de linguagem bastante comum. Aparentemente desprovida de preocupações estéticas, é uma literatura cons- truída na assunção de contraposição a uma postura acadêmica, erudita, ou como uma receita - condescendente - orientada para o que "as massas" apreciariam.

O sentido de domesticidade, ou os seus valores - tomados frequentemente como caraterísticos dessas mulheres leitoras, como é sugerido acima - podem ganhar um novo matiz nessa literatura. Temas e ideias familiares, e até personagens recorrentes, fornecem o aconchego do já conhecido. Domesticidade casa com repetição tranquilizante e com evitação do que é novo.

Assim, de forma concisa, a novela light incorpora as fórmulas repetitivas, os enredos, temas e personagens estereotipados, a emocionalidade do kitsch e uma estética e ideologia semelhantes.

Aqui, o contributo de Jameson surge como resposta que frisa a complexidade dessa questão: não se trata de reduzir o apreço manifestado pela cultura de massas, partilhado por várias classes sociais, a uma vã distração ou a uma mera consciência falsa de quem lê, nesse caso. Importa, antes, compreender como sua fruição proporciona "um trabalho transformacional sobre ansiedades e fantasias sociais e políticas", que é "gerido" na tensão entre a simultânea satisfação e a repressão do desejo (Jameson, 1980).

Além de tudo mais - e não em oposição total a Calinescu, mas indo além do seu ponto de vista -, adiro à ênfase colocada por Radway (1984) ou Sweeney (2010) no fato de a leitura ser também instância para agência e resistência, podendo as leitoras apropriar-se das narrativas para diferentes fins. Assim, equiparar uma experiência vicarial a falsidade ou autodecepção é, parece-me, um juízo demasiado simplista e redutor. Como nota Olalquiaga (1998), e recordando Walter Benjamin, em tempos de crise, o símbolo é esvaziado de significado e a alegoria toma o seu lugar, como forma externa que assumirá novos significados no processo de apropriação. O kitsch é, então, uma resposta que assume a forma de sensibilidade da per- 
da, sustentando-se na recriação de memórias ou de fantasias de um passado idílico. Essa perspectiva que adoto permite superar leituras deterministas do significado do kitsch, assim como evitar o rótulo estigmatizante de uma autodecepção ao frisar o papel da apropriação e recriação pessoais. Entendo, ainda assim, que a produção dos textos analisados não deixa de se basear na repetição, no estereótipo, numa ideologia socialmente regressiva.

Algumas observações adicionais sobre o consumo de literatura industrial: apesar de outras categorias poderem cumprir os critérios, segundo as entrevistadas, de uma leitura apreciada - com a eventual exceção do final feliz -, a única categoria de romance maciçamente presente na biblioteca é precisamente a light. É conhecido, mas será conveniente reforçar, que diversas pessoas, incluindo as e os leitores intensivos de outros gêneros, consomem essa literatura, em perfis cumulativos de leitura. Várias profissionais, nesse serviço educativo, apreciam-na também. Ora, este é o momento para realçar que o que se lê mais dentro da prisão corresponde ao que mais se vende cá fora.

Se as apropriações são as táticas dos fracos (Certeau, 1990) e corroboram, não negando, portanto, as relações de dominação, entendo essas apropriações da leitura na pri๑ são como formas de contornar debilidades na స procura e inadequações na oferta, construindo experiências de leitura a partir daquilo que สี está ao alcance da mão, ou seja como opções s feitas no âmbito de fortes constrangimentos.

\& outras, as opções de leitura surgiram quase iิ por completo, pela primeira vez, dentro da

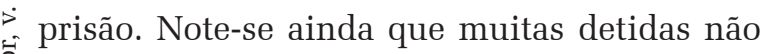
têm acesso, na prática, à biblioteca prisional, e que esse acesso seria restringido, com toda a probabilidade e em analogia com outros estabelecimentos, em caso de punição.

\section{CONCLUSÕES}

Uma nova alocação de tempo, a disponibilidade de livros na biblioteca e a escolarização têm levado à promoção da leitura no EPE de Santa Cruz do Bispo. É em reclusão que muitas das mulheres detidas acabam por ter um contato primeiro com uma biblioteca e com a leitura de lazer, o que reenvia para as deficientes ou inexistentes oportunidades sociais para o fazerem fora da prisão. A biblioteca e a leitura na prisão desempenham um papel de relevo nas sociabilidades das detidas.

As preferências de leitura das detidas variam, estendendo-se por gêneros literários e mostrando combinações individuais de gosto. Os romances cor-de-rosa, industriais ou light são os mais apreciados, num modo de leitura complexo, associando emocionalidade e reflexividade, convocadas para o trabalho interior requerido por processos identitários, assentes tanto em avaliação do passado como em projetos de vida futura. Os modos de leitura escapista e de entretenimento têm lugar importante também entre as práticas de leitura, registrando-se ainda um modo de aquisição de conhecimento.

A análise de romances atualmente rotulados como light permite concluir que eles constituem versões contemporâneas do romance rosa e kitsch, partilhando com eles diversos dos seus traços.

Essa literatura, com frequentes referências ideológicas regressivas, é produzida com claras finalidades de comercialização em massa. Contudo, deve notar-se que preconceitos sociais de classe e de gênero tendem a vir à superfície em muitas das críticas que lhe são dirigidas, e que, como tal, merecem ser desconstruídas. É importante ainda salientar que as interpretações pessoais e as finalidades pessoais atribuídas à leitura se refletem nas apropriações táticas das leitoras detidas, as quais usam a literatura light como um meio disponível para lidar com sua vida de encarceramento, no que revelam uma margem de manobra possível como atoras sociais. 
Esta investigação suscitou ainda a necessidade de compreensão de como o prazer estético estará incorporado nesses modos de leitura e associado a seus objetos, o que entendo carecer de exploração posterior.

Entretanto, não proponho que bibliotecas de prisão - ou outras - devam ter uma abordagem preconceituosa, banindo a literatura industrial. Proponho, sim, que promovam, a partir de práticas de leitura grupal e crítica dessas e de outras obras, a diversificação de gêneros, autores e estilos que possam, efetivamente, facilitar a formação dos gostos e que ampliem as possibilidades de desenvolver modos de ler diversos.

\section{AGRADECIMENTOS}

Às mulheres detidas no EPE de Santa Cruz o meu especial reconhecimento pela forma aberta e entusiasmada como colaboraram com esta pesquisa. A seu pedido, aqui deixo o apelo que me transmitiram: "Não se esqueçam de nós. Aqui dentro, e nestes tempos, temos sempre imenso receio que se esqueçam de que nós existimos".

A conversa com Miguel Horta, animador de leitura em prisões em Portugal, foi particularmente enriquecedora para este trabalho, nomeadamente ao permitir alguma comparação com os contextos prisionais masculinos.

O meu agradecimento a diversas amigas e amigos, por partilharem comigo os seus gostos e desgostos de leitura e por me terem apoiado com suas perspectivas do que ler literatura industrial representa.

Recebido para publicação em 28 de julho de 2014 Aceito em 01 de agosto de 2015

\section{REFERÊNCIAS}

ÁLVAREZ, Carolina.; ÁLVAREZ, Nicolás. Hábitos lectores en el CCP Colina I: una aproximación cualitativa a la experiencia de lectura en las cárceles. Serie Bibliotecología y Gestión de Información, n. 67, 2011. Disponível em: http://hdl.handle.net/10760/16139.
AMORÓS, Andrés. Sociología de una novela rosa. Madrid: Taurus, 1968

ÁVILA, Patrícia. A literacia dos adultos. Tese de Doutoramento. Lisboa: ISCTE, IUL, 2006. Disponível em: https://repositorio.iscte-iul.pt/handle/10071/577.

BARONE, Richard M. De-programming prison libraries. Special Libraries, v. 68, n. 9, 1977. p. 293-298.

BOSWORTH, Mary. Confining femininity: a history of gender, power and imprisonment. Theoretical Criminology, 00023, v. 4, n. 3, ago. 2000. p. 265-284.

CALINESCU, Matei. Five faces of modernity: modernism, avant-garde, decadence, kitsch, postmodernism. Durham: Duke University Press, 1987.

CERTEAU, Michel de. Linvention du quotidien: art de faire. 2nd. ed. Paris: Gallimard, 1990.

COELHO, Paulo. Onze minutos. $2^{\mathrm{a}}$ ed. Cascais: Pergaminho, 2007.

CUNHA, Manuela Ivone. Entre o bairro e a prisão. Lisboa: Fim de Século, 2002

D'HAEN, Theo; DAMROSCH, David; KADIR, Djelal, eds. 2011. The routledge companion to world literature. Abingdon: Routledge.

EIRAS, Bruno Duarte. Uma janela para o mundo: bibliotecas e bibliotecários em meio prisional. 2007, Ponta Delgada. Anais... Ponta Delgada: BAD, 2007. p. 7. Disponível em: www.apbad.pt/Downloads/congresso9/ COM59.pdf.

FELSKI, Rita. Kitsch, romance fiction and male paranoia: Stephen King meets the Frankfurt School. Continuum: the Australian Journal of Media \& Culture, v. 4, n. 1, 1990. Disponível em: http://wwwmcc.murdoch.edu.au/ ReadingRoom/4.1/Felski.html.

Doing time: feminist theory and postmodern culture. New York: NYU Press, 2000.

FERRARO, Kathleen J.; MOE, Angela M. Women's stories of survival and resistance. In: ZAITZOW, Barbara H.; THOMAS, Angela M. (Orgs.). Women in prison: gender and social control. London: Lynne Rienner, 2003. p. 65-93.

FONSECA, Cristina Reis. Crime e castigo: as mulheres na prisão. Coimbra: Almedina, 2010.

GOFFMAN, Erving. Asylums: essays on the social situation of mental patients and other inmates. Garden City, N.Y.: Anchor Books, 1961.

GOMES, Maria do Carmo. Literexclusão na vida quotidiana. Sociologia, Problemas e Práticas, n. 41, 2003 p. 63-92. Disponível em: http://www.scielo.mec.pt/pdf/ spp/n41/n41a03.pdf

HORTA, Miguel; MARQUES, Alexandra. Reclusas preferem casos de amor e policiais duros. Jornal de Notícias, Porto, ago. 2008. Disponível em: http://www.jn.pt/PaginaInicial/ Sociedade/Interior.aspx?content_id=994399.

LOPES, Paula Cristina. Hábitos de leitura em Portugal: uma abordagem transversal-estruturalista de base extensiva. Covilhẫ: UBI, 2011. Biblioteca Online de Ciências da Comunicação. Disponível em: http://www.bocc.ubi.pt/ pag/lopes-paula-habitos-de-leitura-em-portugal.pdf.

MATOS, Raquel.; MACHADO, Carla. Reclusão e laços sociais: discursos no feminino. Análise Social, v. XLII, n. 185, 2007. p. 1041-1054. Disponível em: http:// www.scielo.oces.mctes.pt/scielo.php?pid = S0003 $25732007000400005 \&$ script $=$ sci_arttext .

MENDES, José Manuel. O desafio das identidades. In: SANTOS, Boaventura de Sousa. (Org.). Globalização: fatalidade ou utopia? Porto: Afrontamento, 2001. p. 489-523.

MYERS, Tamara. Criminal women and bad girls: regulation and punishment in Montréal, 1890-1930. Montréal: 
McGill University, 1996. Disponível em: < http://digitool. library.mcgill.ca/R/?func $=$ dbin-jump-full\&object id =40209\&local_base $=$ GEN01-MCG02 >

MODIGNANI, Sveva Casati. Uma chuva de diamantes. Porto: Asa, 2006.

NOGUEIRA, Patrícia. 3 Horas para Amar [filme]. Porto: ESMAE / IPP, 2013

OLALQUIAGA, Celeste. The artificial kingdom: a treasury of the kitsch experience. New York: Pantheon Books, 1998.

PEREIRA, Ana Cristina; PIMENTA, Rita; MIRANDA, Adriano. Ler é fugir daqui. Público, Porto, 2 out. 2011. p. 18-35.

PEREZ PULIDO, Margarita. Programs promoting reading in Spanish prisons. IFLA Journal, v. 36, n. 2, jul. 2010. p. 131-137.

PINHO, Nuno.; TEIXEIRA, Samuel.; FERREIRA, Sónia. Saber o bem que se quer: sei lá, de Margarida Rebelo Pinto e Oficina do Livro, como caso de sucesso em marketing editorial [pre-print]. Aveiro: Universidade de Aveiro, 2009. Disponível em: <http://pt.scribd.com/doc/17165076/ Versao-preliminar-Nuno-Pinho-Samuel-Teixeira-SoniaFerreira-Marketing-do-Livro-Sei-La $>$.

RADWAY, Janice. Reading the romance: women, patriarchy, and popular literature. Chapel Hill: University of North Carolina Press, 1984.
ROBERTS, Nora. Um sonho de vida. Sintra: Arte Plural, 2005 .

SWEENEY, Megan. Prison narratives, narrative prisons: incarcerated women reading Gayl Jones's "Eva's Man". Feminist Studies, v. 30, n. 2, 2004. p. 456-483.

Reading and reckoning in a women's prison. Texas $\overline{\text { studies }}$ in literature and language. v. 50, n. 3, 2008. p. 304328.

. Reading is my window: books and the art of reading in women's prisons. Chapel Hill: University of North Carolina Press, 2010

WACQUANT, Loïc. Crafting the neoliberal state: workfare, prisonfare, and social insecurity. Sociological Forum, v. 25, n. 2, 2010. p. 197-220. Disponível em: http://loicwacquant. net/assets/Papers/CRAFTINGNEOLIBERALSTATE-pub. pdf.

Três etapas para uma antropologia histórica do neoliberalismo realmente existente. Caderno CRH, v. 25, n. 66, 2012. p. 505-518. Disponível em: http://www.cadernocrh.ufba.br/include/getdoc. php?id $=2825 \&$ article $=1119 \&$ mode $=$ pdf.

ZAITZOW, Barbara H.; THOMAS, Jim (orgs.). Women in prison: gender and social control. London: Lynne Rienner, 2003. 


\section{READING IN WOMEN'S PRISON: from the library to questioning tastes}

\section{Paula Sequeiros}

A women's prison in Portugal was the case study about reading practices in this environment. The female prison system (M.I. Cunha and C.R. Fonseca) and a feminist comparative perspective (M. Bosworth, B.H. Zaitzow \& J. Thomas) were used as reference. In order to understand what, why and with what meanings these women read, crossing social dimensions, this study had a qualitative approach with different methodologies (ethnography, individual and group interviews with readers and mediators), and included uses of the physical and social spaces and of time, family relations, relations with other inmates and with the prison staff. The favorite titles were analyzed (chick lit, industrial, light and kitsch literature), taking into account literary genres for women and deconstructing gender and class prejudices that were connected to them. Interpretation was carried out with a diverse theoretical chart (A. Amorós, M. Calinescu, R. Felski, J. Radway and M. Sweeney). The analysis of practices, concepts and representations revealed interesting and eventually unexpected traces about their forms of reading.

KEYwORDS: Women's prison. Reading. Light literature. Kitsch literature. Chick lit.

\section{LA LECTURE DANS UNE PRISON FÉMININE: de la bibliothèque à la question des goûts}

Paula Sequeiros

Une prison de femmes au Portugal a fait l'objet d'une étude sur les pratiques de lecture dans le cadre de ce quotidien. Le système pénitentiaire féminin (M.I. Cunha e C.R. Fonseca) et une perspective féministe et comparative (M. Bosworth, B.H. Zaitzow \& J. Thomas) ont servi de référence à cette étude. Afin de comprendre le quoi, le pourquoi et en vue de quoi les femmes prisonnières lisent, et après avoir fait des croisements entre les diverses dimensions sociales, une approche qualitative a pu être élaborée, diversifiée sur le plan méthodologique (ethnographie, interviews individuelles et en groupes avec les lectrices et avec des intermédiaires) en y incluant l'utilisation de l'espace physique et social ainsi que la dimension du temps, les relations avec des membres de la famille, d'autres prisonnières et le personnel pénitentiaire. Les livres préférés ont été analysés (romans à l'eau de rose, littérature industrielle, light ou kitsch), en tenant compte des genres littéraires destinés au public féminin et en déconstruisant les préjugés de genre et de classe accompagnant leur critique. Linterprétation a été construite dans un cadre théorique diversifié (A. Amorós, M. Calinescu, R. Felski, J. Radway e M. Sweeney). L'analyse des pratiques, des conceptualisations et des représentations a dévoilé des traits intéressants voire inattendus concernant les modes de lecture.

Mots-CLÉs: Prisons de femmes. Lecture. Littérature light. Littérature kitsch. Romans à l'eau de rose.

\footnotetext{
Paula Sequeiros - Doutora em Sociologia. Pesquisadora de pós-doutoramento no Centro de Estudos Sociais na Universidade de Coimbra. Investigadora Associada do Instituto de Sociologia da Universidade do Porto. A sua pesquisa incide sobre usos e práticas nas bibliotecas públicas na sua relação com a leitura e as novas tecnologias. Publicações recentes: Public library representations and internet appropriations. Forum Qualitative Sozialforschung/Forum: Qualitative Social Research. Berlin: v. 15, n. 1. 2014. http://www.qualitative-research.net/index.php/fqs/article/view/2007; Adozinda Goes to the feminine reading room: a segregated space for women in a Portuguese Public Library under a Fascist State. In: Narratives and social memory: theoretical and methodological approaches. University of Minho, p. 327-343, 2013; em coautoria. Grünig, Silvia. A tale of two libraries: space, place and reading in Porto's public libraries,. In: Libraries driving access to knowledge. de Gruyter Saur; IFLA, p. 247-288, 2012.
} 
